\title{
Prevalence and Determinants of Gastrointestinal Symptoms in Adults on Maintenance Hemodialysis in Cameroon
}

\author{
Francois Folefack Kaze ${ }^{1,2^{*}}(\mathbb{D})$, Mathurin Pierre Kowo ${ }^{1,2}{ }^{\circledR}$, Ethel Ngweh-Awah Anyu Ndikum ${ }^{3}$, \\ Hermine Danielle Menye Ebana Fouda', Victorine Nzana ${ }^{1,2}$, Emmanuelle Ndjong2, \\ Marie Patrice Halle 4
}

${ }^{1}$ Department of Internal Medicine and Specialties, Faculty of Medicine and Biomedical Sciences, University of Yaounde 1, Yaounde, Cameroon

${ }^{2}$ Departement of Internal Medicine, Yaounde University Teaching Hospitals, Yaounde, Cameroon

${ }^{3}$ Higher Institute of Health Sciences, Bangangté, Cameroon

${ }^{4}$ Department of Clinical Sciences, Faculty of Medicine and Pharmaceutical Sciences, University of Douala, Douala, Cameroon Email: ^f_kaze@yahoo.fr, kowomathurinp@yahoo.fr, ndikumanyu@yahoo.fr,mendjouf@yahoo.fr, vickybandolo@yahoo.fr, endjong@yahoo.fr, patricehalle@yahoo.fr

How to cite this paper: Kaze, F.F., Kowo, M.P., Ndikum, E.N.-A.A., Fouda, H.D.M.E., Nzana, V., Ndjong, E. and Halle, M.P. (2020) Prevalence and Determinants of Gastrointestinal Symptoms in Adults on Maintenance Hemodialysis in Cameroon. Open Journal of Nephrology, 10, 212-222. https://doi.org/10.4236/ojneph.2020.103020

Received: June 11, 2020

Accepted: July 5, 2020

Published: July 8, 2020

Copyright $\odot 2020$ by author(s) and Scientific Research Publishing Inc. This work is licensed under the Creative Commons Attribution International License (CC BY 4.0).

http://creativecommons.org/licenses/by/4.0/

\section{(c) (i) Open Access}

\begin{abstract}
Introduction: Gastrointestinal symptoms (GIS) are common in patients on maintenance hemodialysis and constitute an important cause of morbidity. Objectives: To determine the prevalence of GIS and identify their determinants in adults on maintenance hemodialysis in Cameroon. Patients and Methods: This hospital-based cross-sectional study was conducted from January to May 2017 at the Yaounde University Teaching Hospital dialysis center. All conscious consenting adults' patients who provided a written informed consent and have been on hemodialysis for more than three months with an arterio-venous fistula were recruited. All chronic hemodialysis patients of the center dialyze 4 hours twice a week. All patients with dementia were excluded. We collected demographic, clinical, and paraclinical data and used Rome IV modified GIS rating scale. Parametric and non-parametric tests were used to compare variables. Results: We included 83 (72.3\% males) participants with a mean (SD) age of 50 (12) years. Hypertension (31.3\%), chronic glomerulonephritis (26.5\%) and diabetes mellitus (20.5\%) were the leading baseline nephropathy. There were 31 (37.3\%) participants with psychiatric disorders including anxiety (45.2\%) and depression (54.8\%). The biological abnormalities were increased parathormone (20.5\%), hypocalcemia (24.1\%), hyperphosphatemia (32.5\%), increased C-reactive protein $(46.4 \%)$ and anemia (68.7\%). The GIS was reported in 73 (87.9\%) participants. Diar-
\end{abstract}


rhea (47\%), constipation (38.6\%), vomiting (38.6\%), anorexia (33.7\%) and nausea $(31.3 \%)$ were the main GIS observed. The presence of hypertension was the only association with the GIS ( $p=0.02$ ). We did not find any association between GIS and age, gender, diabetes mellitus, psychiatric disorders and duration in dialysis (all $\mathrm{p}>0.1$ ). Conclusion: We reported a high prevalence of GIS in this mainly young adult population. This could be related to their under-dialysis status and suggest the increased frequency of dialysis session in this setting.

\section{Keywords}

Gastrointestinal Symptoms, Adults, Hemodialysis, Cameroon

\section{Introduction}

Gastrointestinal symptoms (GIS) are common in patients on maintenance hemodialysis (HD) and constitute an important cause of morbidity. Studies revealed a high prevalence of GIS ranging from $51 \%$ to $79 \%$ in chronic hemodialyzed patients [1]-[7]. They are dominated by nausea, vomiting, abdominal pain, constipation, and diarrhea, and cause major impairment of daily life activities [1] [8]. These GIS could be improved, worsened or not influenced by hemodialysis [2] [8] [9] [10] [11].

The pathophysiology of GIS is multifactorial; GIS could be related to the increased concentration of gastrointestinal (GI) hormones (gastrin, cholecystokinin, gastric inhibitory peptide and glucagon), the presence of Helicobacter pylori, the alterations of colonic flora due to uremic molecules retention in GI tract, lifestyle changes, anxiety and depression, and the gastroparesis with higher gastric retention and prolonged gastric emptying [8] [12]. The GIS are functional or organic regarding the absence or presence of GI lesions respectively. The functional disorders are highly frequent in patient on maintenance HD and associated with psychological factors, visceral hypersensitivity, and altered GI motility [8] [9] [10].

Studies in patients on maintenance HD revealed that GIS are more severe in older patients compared to younger, more common in females, associated with comorbidities (hypertension, diabetes and heart disease) and impairment in psychological general well-being, favored by poor nutritional status, and increase with the duration in dialysis [2] [13] [14] [15].

In sub-Saharan Africa setting, there is a dearth of literature assessing the GIS in chronic HD. It's important to characterize the magnitude of the problem regarding the potential benefit of L-Carnitine supplementation on the improvement of muscle discomfort and GIS in such patients [16]. We therefore undertake this study aiming to determine the prevalence of GIS and identify their determinants in patients on maintenance HD in the Yaounde University Teaching Hospital dialysis center. 


\section{Patients and Methods}

\subsection{Study Design and Setting}

The Yaounde University Teaching Hospital (YUTH) dialysis center served as the setting of this hospital-based cross-sectional study conducted from January to May 2017. The center had 10 Nipro Surdial $^{\mathrm{TM}}-55$ plus HD generators (Nipro Medical Devices, Osaka, Japan) and operates HD with synthetic polysulfone dialysis membrane, bicarbonate and heparin. All chronic HD patients of the center dialyze 4 hours twice a week from Monday to Saturday. Ethical approval and administrative authorization were obtained from the ethic committee of the Higher Institute of Health Sciences of Bangangté in Cameroon and the YUTH respectively.

\subsection{Data Collection}

All consenting adults ( $\geq 18$ years old) patients who provided a written informed consent and have been on HD for more than three months with an arterio-venous fistula were recruited. All patients with dementia were excluded. All patients, assisted by the investigator who was a final year's undergraduate medical student, filled a pre-tested questionnaire; it includes demographic (age, sex and employment status), clinical (comorbidities, baseline nephropathy, duration in dialysis, blood pressure, weight, height and GIS) and paraclinical (calcemia, phosphatemia, parathormone, albuminemia, hemoglobin, C-reactive protein) data. We used the Rome IV modified GIS rating scale to collect abdominal bloating and pain, anorexia, burping, constipation, diarrhea, dysphagia, epigastric pain, heart burn, nausea, vomiting and postprandial swelling [17]. All chronic HD patients of the center had a routine psychiatric evaluation every three months and when indicated. The diagnosis of anxiety and depression was made by a psychiatrist.

\subsection{Definitions}

We considered obesity as body mass index (BMI) $\geq 30 \mathrm{~kg} / \mathrm{m}^{2}$ whereas hypertension was defined as the presence of systolic blood pressure (SBP) $\geq 140 \mathrm{mmHg}$ and/or diastolic blood pressure (DBP) $\geq 90 \mathrm{mmHg}$ at the beginning of the dialysis session. Anemia was defined by haemoglobin level $<10 \mathrm{~g} / \mathrm{dL}$. Hypocalcemia was defined by a serum calcium level $<80 \mathrm{mg} / \mathrm{l}$ after correction with albuminemia whereas hyperphosphatemia corresponded to a serum phosphate level $>50 \mathrm{mg} / \mathrm{l}$. Increased parathormone (PTH) level was considered when a serum PTH level was above 9 times the upper limit of the normal value ( $>70 \mathrm{pg} / \mathrm{ml})$. Hypoalbuminemia was a serum albumin level $<30 \mathrm{~g} / \mathrm{l}$ while increased C-reactive protein (CRP) corresponded to a serum level $>6 \mathrm{mg} / \mathrm{l}$.

\subsection{Statistical Analysis}

We entered and coded data using EPI info version 7.0 whereas statistical analysis used Statistical Package for Social Science (SPSS) version 23.0 and CSpro version 6.3. We used mean and standard deviation (SD), and median and interquartile range (IQR) where appropriate for continuous variables while frequencies and 
proportions were computed for categorical variables. Chi-square test and equivalents, and Student t-test and non-parametric equivalents were used to compare qualitative and quantitative variables. The level of significance was set at $\mathrm{p}<0.05$.

\section{Results}

\subsection{Socio-Demographic and Clinical Characteristics of the Study Population}

As presented in Table 1, we included 83 participants with a mean (SD) age of 50 (12) years among whom 60 (72.3\%) males and 22 (26.5\%) unemployed. Hypertension (97.6\%), diabetes mellitus (26.5\%) and gout (20.5\%) were the main comorbidities whereas hypertension (31.3\%), chronic glomerulonephritis (26.5\%) and diabetes mellitus (20.5\%) were the leading baseline nephropathy. We observed that $60(72.3 \%)$ participants had hypertension while 8 (9.6\%) were obese. There were $31(37.3 \%)$ study participants with psychiatric disorders among which 14 (45.2\%) had anxiety and 17 (54.8\%) depression.

\subsection{Paraclinical Characteristics of the Study Population}

We observed a high prevalence of participants with abnormalities of mineral bone disease including 20 (24.1\%) with hypocalcemia, 27 (32.5\%) with hyperphosphatemia and 17 (20.5\%) with increased PTH as outlined in Table 2. Anemia was reported in 57 (68.7\%) participants while $36(46.4 \%)$ had an increased CRP.

\subsection{Type and Frequency of Gastrointestinal Symptoms}

In Figure 1, we showed that 73 (87.9\%) study participants had at least one GIS. Diarrhea (47\%), constipation (38.6\%), vomiting (38.6\%), anorexia (33.7\%) and nausea $(31.3 \%)$ were the main GIS observed among the study population.

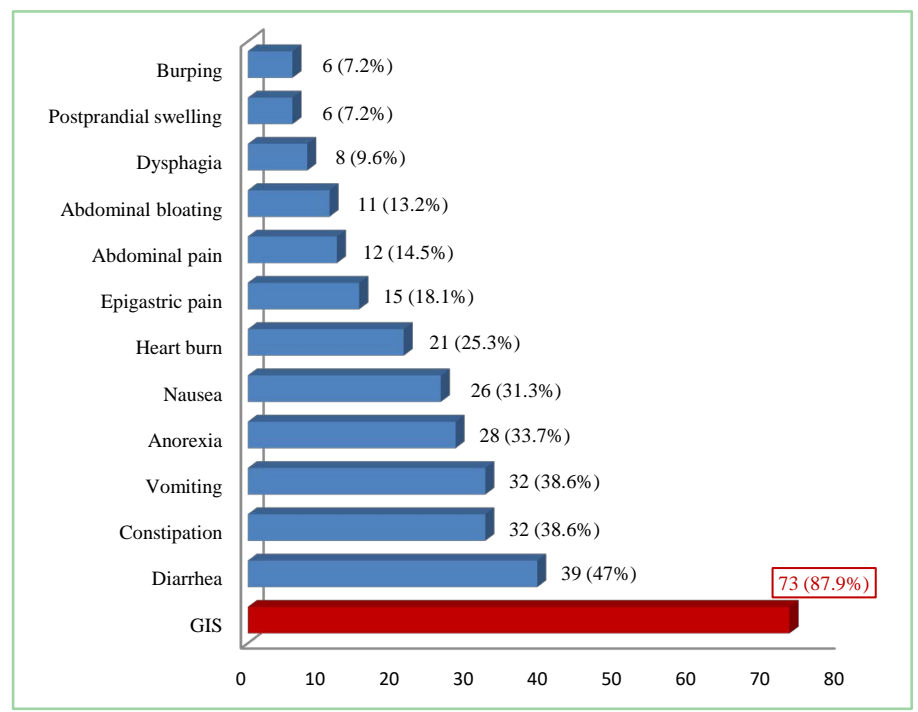

Figure 1. Type and frequency of gastrointestinal symptoms. GIS-gastrointestinal symptoms. 
Table 1. Socio-demographic and clinical characteristics of the study population.

\begin{tabular}{|c|c|}
\hline Variables & $\mathrm{N}(\%)$ \\
\hline Total & $83(100)$ \\
\hline Mean age (SD), years & $50(12)$ \\
\hline \multicolumn{2}{|l|}{ Sex } \\
\hline Male & $60(72.3)$ \\
\hline Female & $23(27.7)$ \\
\hline \multicolumn{2}{|l|}{ Employment } \\
\hline Yes & $61(73.5)$ \\
\hline No & $22(26.5)$ \\
\hline \multicolumn{2}{|l|}{ Comorbidities } \\
\hline Hypertension & $81(97.6)$ \\
\hline Diabetes & $22(26.5)$ \\
\hline Gout & $17(20.5)$ \\
\hline HIV & $6(7.2)$ \\
\hline $\mathrm{HBV}$ & $2(2.4)$ \\
\hline \multicolumn{2}{|l|}{ Baseline nephropathy } \\
\hline Hypertension & $26(31.3)$ \\
\hline Chronic glomerulonephritis & $22(26.5)$ \\
\hline Diabetes & $17(20.5)$ \\
\hline ADPKD & $4(4.8)$ \\
\hline Chronic tubulo-interstitial nephritis & $3(3.6)$ \\
\hline HIVAN & $3(3.6)$ \\
\hline Undetermined & $8(9.6)$ \\
\hline \multicolumn{2}{|l|}{ Psychiatric disorders } \\
\hline Yes & $31(37.3)$ \\
\hline No & $52(62.7)$ \\
\hline Mean SBP (SD), mmHg & $157.3(23.9)$ \\
\hline Mean DBP (SD), mmHg & $88.03(16.1)$ \\
\hline Hypertension, $\mathrm{n}(\%)$ & $60(72.3)$ \\
\hline Mean BMI (SD), $\mathrm{Kg} / \mathrm{m}^{2}$ & $24.9(3.6)$ \\
\hline Obese, n (\%) & $8(9.6)$ \\
\hline
\end{tabular}

ADPKD—Autosomal dominant polycystic kidney disease; BMI-Body mass index; DBP—Diastolic blood pressure; HBV-Hepatitis B virus; HIV-Human immunodeficiency virus; HIVAN-HIV associated nephropathy; SBP-Systolic blood pressure; SD—Standard deviation. 
Table 2. Paraclinical characteristics of the study population.

\begin{tabular}{cc}
\hline Variables & $\mathbf{N}(\%)$ \\
Total & $83(100)$ \\
Mean calcemia (SD), mg/l & $84.7(13.4)$ \\
Hypocalcemia, $\mathrm{n}(\%)$ & $20(24.1)$ \\
Median phosphatemia (IQR), mg/l & $45.2(34.7-53.9)$ \\
Hyperphosphatemia, $\mathrm{n}(\%)$ & $27(32.5)$ \\
Median parathormone, (IQR), pg/ml & $605.6(294.7-1137.0)$ \\
Increased parathormone, $\mathrm{n}(\%)$ & $17(20.5)$ \\
Mean albuminemia (SD), g/l & $40.8(5.7)$ \\
Hypoalbuminemia, $\mathrm{n}(\%)$ & $1(1.2)$ \\
Mean hemoglobin (SD), g/dl & $9(1.8)$ \\
Anemia, $\mathrm{n}(\%)$ & $57(68.7)$ \\
Median CRP (IQR), mg/l & $6(2.4-20.3)$ \\
Increased CRP, $\mathrm{n}(\%)$ & $36(43.4)$ \\
\hline
\end{tabular}

CRP-C-reactive protein; IQR-interquartile range; $\mathrm{SD}-$ standard deviation.

\subsection{Determinants of Gastrointestinal Symptoms}

We found that hypertension was the only associated factor of GIS ( $p=0.02)$. We did not find any association between GIS and age, gender, diabetes mellitus, psychiatric disorders and duration in dialysis (all $\mathrm{p}>0.1$ ), Table 3.

\section{Discussion}

This study on the prevalence and determinants of GIS in adults on maintenance $\mathrm{HD}$ in Cameroon revealed a high prevalence occurring in nearly nine out of ten participants leading by diarrhea, constipation, vomiting, anorexia and nausea. The presence of hypertension was the only determinant of GIS observed in this study.

The profile of patients on maintenance HD is similar to the one previously observed in this setting. Chronic HD patients are mainly young male adults with hypertension and diabetes mellitus as leading etiological factors and comorbidities [18] [19] [20].

We observed a high prevalence of GIS occurring in $87.9 \%$ similar to the prevalence in geriatric population [21]. This prevalence was very high compare to frequencies reported in the literature [1]-[7]. This high prevalence of GIS could reflect the under-dialysis status of these patients in relation to the reduced frequency at two weekly dialysis session compare to the three sessions recommended by guidelines; moreover, GIS are mainly uremic symptoms which are not directly affected by dialysis treatment or dialysis unit care [11]. The type and profile of GIS were similar to those observed elsewhere with some differences in their frequencies [1] [4] [5] [14]. These GIS could be explained by the poor appetite in these patients in relation to under-dialysis status [22]. 
Table 3. Determinants of gastrointestinal symptoms.

\begin{tabular}{cccc}
\hline Variables & \multicolumn{2}{c}{ Gastrointestinal manifestations } & \multirow{2}{*}{ p-value } \\
\cline { 2 - 3 } & Yes & No & \\
\hline Mean age (SD) & $51.1(11.6)$ & $45.7(13.9)$ & 0.13 \\
Male sex, n (\%) & $50(83.3)$ & $10(16.7)$ & 0.70 \\
Median BMI (IQR) & $23.8(22.7-26.6)$ & $24.5(23.4-28.4)$ & 0.49 \\
Unemployment, n (\%) & $15(78.9)$ & $5(21.1)$ & 0.50 \\
Psychiatric disorders, n (\%) & $29(88.2)$ & $2(11.8)$ & 0.10 \\
Median duration in dialysis (IQR) & $15(6.8-48.0)$ & $24(8.5-56.5)$ & 0.40 \\
Hypertension, n (\%) & $70(86.4)$ & $11(13.6)$ & 0.02 \\
Diabetes, n (\%) & $20(90.9)$ & $2(9.1)$ & 0.50 \\
Median hemoglobin (IQR) & $8.8(7.6-10.2)$ & $9.2(8.3-10.1)$ & 0.35 \\
Median parathormone (IQR) & $462.9(260.4-1007.9)$ & $873.1(669.0-1261.0)$ & 0.10 \\
Median calcemia (IQR) & $84.9(79.2-95.8)$ & $84(77.0-92.3)$ & 0.59 \\
Median phosphatemia (IQR) & $44.4(33.0-53.0)$ & $51.9(42.2-57.0)$ & 0.09 \\
Median albuminemia (IQR) & $41(36.8-44.0)$ & $40(38.1-42.4)$ & 0.64 \\
Median CRP (IQR) & $4(1.0-18.5)$ & $2(0.0-8.0)$ & 0.22 \\
\hline
\end{tabular}

BMI-Body mass index; CRP-C-reactive protein; IQR - Interquartile range; SD—Standard deviation.

The presence of hypertension was the only associated factors to the presence of GIS as previously observed [13]. This association suggests that a strict control of blood pressure could be of help in the management of GIS. As reported in Asian patients, we did not found an association between the presence of GIS and diabetes mellitus [7]. Our study did not report any association between age as well gender and the presence of GIS as observed in such patients elsewhere [13] [14] [21]. We did not observe any association between the presence of GIS and longer duration in dialysis as reported by the literature [2] [13]. Despite the lack of association between the presence of GIS and albuminemia, hemoglobin and CRP level, there is report from the literature showing that anorexia is associated with higher concentrations of proinflammatory cytokines and higher levels of erythropoietin hyporesponsiveness and poor clinical outcome as well as quality of life in patients on maintenance HD [23]. The lack of various associations between the presence of GIS and tested variables who have been reported in the literature could be related to the reduced sample size and frequency of dialysis session in our study participants. This study did not reveal any association between the presence of GIS and psychiatric disorders as observed elsewhere in contrast with others studies which reported a correlation between the presence of GIS and the impaired psychological well-being [7] [10] [15].

\section{Strengths and Limitations}

The main limitations of this study are the lack of endoscopic evaluation as well 
as the assessment of nutritional status and quality of life of these patients. Nevertheless, this study is the first in sub-Saharan Africa setting, to the best of our knowledge, to assess the prevalence and determinants of GIS in adults on chronic HD. This study provides baseline data to have the magnitude of the problem and serves as the basis of further studies to assess the nutritional status, the quality of life and the effect of L-carnitine supplementation in patient with GIS in our setting.

\section{Conclusion}

We reported a high prevalence of GIS in this mainly young adult group similar to the geriatric population. This could be related to the under-dialysis status of these patients. These results suggest the increased frequency of dialysis session in the management of GIS.

\section{Declarations}

\section{Ethic Approval and Consent to Participate}

This study received an administrative authorization from the Yaounde University Teaching Hospital (Number: 741/AR/CHUY/DG/DGA/DMT), and was approved by the ethic committee of the Higher Institute of Health Sciences of Bangangt in Cameroon (Number: 2017/116/UdM/PR/CIE) and all participants provided a written informed consent before enrolment.

\section{Consent for Publication}

All authors gave their approval for publication

\section{Funding}

The authors did not receive any fund for this study.

\section{Authors' Contribution Statement}

Study conception-FFK, ENAAN, MPK

Clinical data collection and supervision-FFK, ENAAN, EN, MPK, VN

Acquisition and validation of the biological data-FFK, HDFME, ENAAN, EN, VN

Data analysis-FFK, MPH

Data interpretation-FFK, MPH

Manuscript drafting-FFK, MPH

Critical revision of the manuscript-HDFME, ENAAN, EN, MPK, VN

\section{Availability of Data and Materials}

Data and material are available with corresponding authors which is the principal investigator. They can be consulted at any time upon request. However, the ethical clearance and the informed consent form did not mention that patient data could be shared with a third party. 


\section{Acknowledgements}

We thank the Yaounde University Teaching Hospital's dialysis staff.

\section{Conflicts of Interest}

The authors declare no conflicts of interest regarding the publication of this paper.

\section{References}

[1] Hammer, J., Oesterreicher, C., Hammer, K., Koch, U., Traindl, O. and Kovarik, J. (1998) Chronic Gastrointestinal Symptoms in Hemodialysis Patients. Wiener Klinische Wochenschrift, 110, 287-291.

[2] Abu Farsakh, N.A., Roweily, E., Rababaa, M. and Butchoun, R. (1996) Brief Report: Evaluation of the Upper Gastrointestinal Tract in Uraemic Patients Undergoing Haemodialysis. Nephrology Dialysis Transplantation, 11, 847-850. https://doi.org/10.1093/oxfordjournals.ndt.a027411

[3] Luzza, F., Imeneo, M., Maletta, M., Mantelli, I., Tancre, D., Merando, G., Biancone, L. and Pallone, F. (1996) Helicobacter Pylori-Specific IgG in Chronic Haemodialysis Patients: Relationship of Hypergastrinaemia to Positive Serology. Nephrology Dialysis Transplantation, 11, 120-124.

https://doi.org/10.1093/oxfordjournals.ndt.a027026

[4] Dong, R., Guo, Z.Y., Ding, J.R., Zhou, Y.Y. and Wu, H. (2014) Gastrointestinal Symptoms: A Comparison between Patients Undergoing Peritoneal Dialysis and Hemodialysis. World Journal of Gastroenterology, 20, 11370-11375. https://doi.org/10.3748/wjg.v20.i32.11370

[5] Zuvela, J., Trimingham, C., Le Leu, R., Faull, R., Clayton, P., Jesudason, S. and Meade, A. (2018) Gastrointestinal Symptoms in Patients Receiving Dialysis: A Systematic Review. Nephrology (Carlton), 23, 718-727. https://doi.org/10.1111/nep.13243

[6] Salamon, K., Woods, J., Paul, E. and Huggins, C. (2013) Peritoneal Dialysis Patients Have Higher Prevalence of Gastrointestinal Symptoms than Hemodialysis Patients. Journal of Renal Nutrition, 23, 114-118. https://doi.org/10.1053/j.jrn.2012.02.007

[7] Chong, V.H. and Tan, J. (2013) Prevalence of Gastrointestinal and Psychosomatic Symptoms among Asian Patients Undergoing Regular Hemodialysis. Nephrology (Carlton), 18, 97-103. https://doi.org/10.1111/nep.12000

[8] Shirazian, S. and Radhakrishnan, J. (2010) Gastrointestinal Disorders and Renal Failure: Exploring the Connection. Nature Reviews Nephrology, 6, 480-492. https://doi.org/10.1038/nrneph.2010.84

[9] Kahvecioglu, S., Akdag, I., Kiyici, M., Gullulu, M., Yavuz, M., Ersoy, A., Dilek, K. and Yurtkuran, M. (2005) High Prevalence of Irritable Bowel Syndrome and Upper Gastrointestinal Symptoms in Patients with Chronic Renal Failure. Journal of Nephrology, 18, 61-66.

[10] Cano, A.E., Neil, A.K., Kang, J.Y., Barnabas, A., Eastwood, J.B., Nelson, S.R., Hartley, I. and Maxwell, D. (2007) Gastrointestinal Symptoms in Patients with End-Stage Renal Disease Undergoing Treatment by Hemodialysis or Peritoneal Dialysis. American Journal of Gastroenterology, 102, 1990-1997. https://doi.org/10.1111/j.1572-0241.2007.01321.x

[11] Chan, C.T., Blankestijn, P.J., Dember, L.M., Gallieni, M., Harris, D.C.H., Lok, C.E., Mehrotra, R., Stevens, P.E., Wang, A.Y., Cheung, M., Wheeler, D.C., Winkelmayer, 
W. and Pollock, C.A. (2019) Dialysis Initiation, Modality Choice, Access, and Prescription: Conclusions from a Kidney Disease: Improving Global Outcomes (KDIGO) Controversies Conference. Kidney International, 96, 37-47. https://doi.org/10.1016/j.kint.2019.01.017

[12] Broberg, B., Madsen, J.L., Fuglsang, S., Holst, J.J., Christensen, K.B., Rydahl, C., Idorn, T., Feldt-Rasmussen, B. and Hornum, M. (2019) Gastrointestinal Motility in Patients with End-Stage Renal Disease on Chronic Hemodialysis. Neurogastroenterology \& Motility, 31, e13554. https://doi.org/10.1111/nmo.13554

[13] Daniels, G., Robinson, J.R., Walker, C., Pennings, J.S. and Anderson, S.T. (2015) Gastrointestinal Symptoms among African Americans Undergoing Hemodialysis. Nephrology Nursing Journal, 42, 539-548.

[14] Silva, L.F., Lopes, G.B., Matos, C.M., Brito, K.Q., Amoedo, M.K., Azevedo, M.F., Sa Araujo, M.J., Martins, M.S. and Lopes, A.A. (2012) Gastrointestinal Symptoms and Nutritional Status in Women and Men on Maintenance Hemodialysis. Journal of Renal Nutrition, 22, 327-335. https://doi.org/10.1053/j.jrn.2011.07.007

[15] Strid, H., Simren, M., Johansson, A.C., Svedlund, J., Samuelsson, O. and Bjornsson, E.S. (2002) The Prevalence of Gastrointestinal Symptoms in Patients with Chronic Renal Failure Is Increased and Associated with Impaired Psychological General Well-Being. Nephrology Dialysis Transplantation, 17, 1434-1439. https://doi.org/10.1093/ndt/17.8.1434

[16] Irie, J., Kanno, Y., Kikuchi, R., Yoshida, T., Murai, S., Watanabe, M., Itoh, H. and Hayashi, M. (2017) L-Carnitine Improves Gastrointestinal Disorders and Altered the Intestinal Microbiota in Hemodialysis Patients. Bioscience of Microbiota, Food and Health, 36, 11-16. https://doi.org/10.12938/bmfh.16-009

[17] Drossman, D.A. (2016) Functional Gastrointestinal Disorders: History, Pathophysiology, Clinical Features and Rome IV. Gastroenterology, 150, 1262-1279. https://doi.org/10.1053/j.gastro.2016.02.032

[18] Kaze, F.F., Kengne, A.P., Mambap, A.T., Halle, M.P., Mbanya, D. and Ashuntantang, G. (2015) Anemia in Patients on Chronic Hemodialysis in Cameroon: Prevalence, Characteristics and Management in Low Resources Setting. African Health Sciences, 15, 253-260. https://doi.org/10.4314/ahs.v15i1.33

[19] Kaze, F.F., Ashuntantang, G., Kengne, A.P., Hassan, A., Halle, M.P. and Muna, W. (2012) Acute Hemodialysis Complications in End-Stage Renal Disease Patients: The Burden and Implications for the Under-Resourced Sub-Saharan African Health Systems. Hemodialysis International, 16, 526-531. https://doi.org/10.1111/j.1542-4758.2012.00692.x

[20] Halle, M.P., Takongue, C., Kengne, A.P., Kaze, F.F. and Ngu, K.B. (2015) Epidemiological Profile of Patients with End Stage Renal Disease in a Referral Hospital in Cameroon. BMC Nephrology, 16, 59. https://doi.org/10.1186/s12882-015-0044-2

[21] Carrera-Jimenez, D., Miranda-Alatriste, P., Atilano-Carsi, X., Correa-Rotter, R. and Espinosa-Cuevas, A. (2018) Relationship between Nutritional Status and Gastrointestinal Symptoms in Geriatric Patients with End-Stage Renal Disease on Dialysis. Nutrients, 10, 425. https://doi.org/10.3390/nu10040425

[22] Bossola, M., Luciani, G., Rosa, F. and Tazza, L. (2011) Appetite and Gastrointestinal Symptoms in Chronic Hemodialysis Patients. Journal of Renal Nutrition, 21, 448-454. https://doi.org/10.1053/j.jrn.2010.09.003

[23] Kalantar-Zadeh, K., Block, G., McAllister, C.J., Humphreys, M.H. and Kopple, J.D. (2004) Appetite and Inflammation, Nutrition, Anemia, and Clinical Outcome in Hemodialysis Patients. American Journal of Clinical Nutrition, 80, 299-307. https://doi.org/10.1093/ajcn/80.2.299 


\section{List of Abbreviations}

ADPKD—Autosomal dominant polycystic kidney disease; BMI—Body mass index; CRP-C-reactive protein; DBP-Diastolic blood pressure; GIS-Gastrointestinal symptoms; HBV-Hepatitis B virus; HIV-Human immunodeficiency virus; HIVAN-HIV associated nephropathy; IQR - Interquartile range; SBP-Systolic blood pressure; SD—Standard deviation 